\title{
A real-time commercial aggregator for distributed energy resources flexibility management
}

\author{
Gianluca Lipari ${ }^{\mathrm{a}, *}$, Gerard Del Rosario ${ }^{\mathrm{b}},{\text { Cristina } \text { Corchero }^{\mathrm{b}} \text {, Ferdinanda Ponci }}^{\mathrm{a}}$, \\ Antonello Monti ${ }^{\text {a }}$ \\ ${ }^{a}$ RWTH Aachen University - Institute for Automation of Complex Power Systems, E. ON Energy Research Center, Aachen, Germany \\ b Catalonia Institute for Energy Research (IREC), Barcelona, Spain
}

\section{A R T I C L E I N F O}

\section{Article history:}

Received 16 December 2016

Received in revised form 8 June 2017

Accepted 6 July 2017

Available online 21 July 2017

\section{Keywords:}

Commercial aggregator

Congestion management

Distributed energy resources

Microgrid

Real-time simulation

Smart grid

\begin{abstract}
A B S T R A C T
With the transition to a more decentralized electricity sector, Distribution System Operators (DSOs) are facing new challenges, as well as new opportunities, deriving from the growing penetration of Distributed Energy Resources (DERs). In fact, an increasing penetration of DERs in Low Voltage (LV) grids likely pushes the system to congestion conditions more easily but also adds additional flexibility potential to the power system. Currently, the demand response solutions implemented in a significant number of countries do not consider aggregation of customers/prosumers at LV level but typically focus on fewer resources of greater individual size (i.e. industrial loads) connected to Medium and High Voltage levels. Hence the system requires a new actor to manage the resources connected at LV level in the most efficient way.

The paper describes the implementation of a real-time Commercial Aggregator, that pools the generation and/or consumption flexibility offered by its customers to provide energy and services to actors within the system. Results of the emulations carried out in the scope of the FP7 European project IDäL are presented, highlighting the effects of the participation of DERs and Microgrids to the congestion management by offering flexibility products through the involvement of the Commercial Aggregator (CA).
\end{abstract}

(C) 2017 Elsevier Ltd. All rights reserved.

\section{Introduction}

The Energy Efficiency Directive (2012/27/EU) became the basis for the development of demand response and aggregators across Europe [1]. In order to implement this Directive, TSOs, DSOs and regulators need to align technical requirements with participants' capabilities so that customers and aggregators are able to participate in ancillary services markets. However, recent experiences have revealed that only market-driven demand response may create new network constraints that constitute a barrier for the development of these programs. For instance, in Belgium DSOconnected consumers participating in R3-DP (tertiary frequency control-dynamic profile) and SDR (strategic reserve) programs may be blocked by DSOs to avoid regional capacity issues [2].

In particular, the grid impact of increasing penetration levels of DERs in LV networks may be positive or negative depending on the degree of coordination between flexibility markets or other trading platforms and distribution system operation. Furthermore, demand-side flexibility levels need to increase parallel to the

\footnotetext{
* Corresponding author.

E-mail address: glipari@eonerc.rwth-aachen.de (G. Lipari).

URL: http://www.acs.eonerc.rwth-aachen.de (G. Lipari).
}

growing DER penetration in order to provide the system with sufficient capacity to avoid congestions at affordable costs for society.

That said, the system requires a new actor to manage the resources connected at LV level in the most efficient way, since small and medium network users do not have the size nor the means to directly participate in electricity markets. In fact, small tertiary and domestic consumers typically stand for $70 \%$ of total consumption, thus there is significant flexibility potential from this type of customers [3]. The aggregator is a new role in the majority of European electricity markets, but is already established in the USA, Australia, South Korea and Japan. In this paper, aggregators are proposed to trade flexibility of medium and small consumers in flexibility markets and sell it to DSOs as a single volume.

The selected application is a short term congestion management scheme to tackle constraints in distribution networks [4].

The introduction of demand response (DR) aggregators in the system can lead to fairer allocations of DR benefits among system operators, aggregators and end-users compared to conventional centralized schemes, where system operators exploit most of DR benefits for themselves [5]. Furthermore, DR aggregators may adapt their bidding strategy to different types of electricity markets in order to optimize their portfolio management, for instance it has been proposed as a price-taker entity in day-ahead markets but a price-maker entity in real-time ones [6]. 


\section{Notation}

\section{Time intervals}

$\Delta_{t 0} \quad$ Duration of pre-activation time interval

$\Delta_{t} \quad$ Duration of activation time interval

\section{Battery system}

$\begin{array}{ll}N & \text { Battery capacity [kWh] } \\ \bar{P}^{B} & \text { Maximum charging power for the battery [kW] } \\ \underline{P}^{B} & \text { Maximum discharging power for the battery }(<0) \\ \overline{S O C} & {[\mathrm{~kW}]} \\ \underline{S O C} & \text { Maximum SOC for the battery [\%] } \\ \end{array}$

\section{Interconnection}

\section{$\bar{P}^{I} \quad$ Grid tie capacity (purchase) $[\mathrm{kW}]$ \\ $\underline{P}^{I} \quad$ Grid tie capacity (sale) $[\mathrm{kW}]$}

\section{Availability reduction factors}

$\begin{array}{ll}K^{p} & \begin{array}{l}\text { Factor associated with undelivered flexibility } \\ \text { (purchase) [\%] }\end{array} \\ K^{s} & \begin{array}{l}\text { Factor associated with undelivered flexibility } \\ \text { (sale) [\%] }\end{array}\end{array}$

\section{Inputs from EMS}

$\begin{array}{ll}S_{S O C}^{I, \Delta_{t 0} 0} & \begin{array}{l}\text { Initial SOC of the battery in the pre-activation time } \\ \text { interval [\%] }\end{array} \\ S O C_{I, \Delta_{t}} & \begin{array}{l}\text { Initial SOC of the battery in the activation time } \\ \text { interval [\%] }\end{array} \\ p_{\Delta_{t 0}}^{B} & \begin{array}{l}\text { Charging }(>0) \text { or discharging }(<0) \text { rate of the bat- } \\ \text { tery in the pre-activation time interval [kW] }\end{array} \\ p_{\Delta_{t}}^{B} & \begin{array}{l}\text { Charging }(>0) \text { or discharging }(<0) \text { rate of the bat- } \\ \text { tery in the activation time interval [kW] }\end{array} \\ p_{\Delta_{t}}^{I} & \begin{array}{l}\text { Power purchased }(>0) \text { or sold }(<0) \text { in the inter- } \\ \text { connection in the activation time interval [kW] }\end{array}\end{array}$

\section{Outputs (activation time interval)}

$$
\begin{array}{ll}
d_{\Delta_{t}}^{B, c} & \text { Battery regulation band (charging) }[\mathrm{kW}] \\
d_{\Delta_{t}}^{B, d} & \text { Battery regulation band (discharging) }(<0)[\mathrm{kW}] \\
d_{\Delta_{t}}^{I, p} & \text { Interconnection regulation band (purchase) }[\mathrm{kW}] \\
d_{\Delta_{t}}^{I, s} & \text { Interconnection regulation band (sale) }(<0)[\mathrm{kW}] \\
d_{\Delta_{t}}^{I, p, r} & \text { Reduced interconnection regulation band (pur- } \\
d_{\Delta_{t}}^{I, s, r} & \text { chase) }[\mathrm{kW}] \\
& \text { Reduced interconnection regulation band (sale) } \\
& (<0)[\mathrm{kW}]
\end{array}
$$

In literature, two main approaches for the control architecture of active distribution networks are proposed, named (i) centralized dispatch and (ii) multi-agent systems (MAS), which is a step towards the distribution of control [7]. In the first approach, the dispatcher solves an optimal dispatch problem constrained by the grid operation limits and centrally controls resources connected to the network. On the other hand, in the MAS approach pieces of software that are able to control a set of electrical systems (either grid portions or individual resources) and also interact with other pieces are assumed. Both approaches are proposed to coexist in the automation architecture developed in the FP7 European project IDE4L $[8,9]$. In this project, the architecture proposed for the DSO is distributed, in the sense that the automation burdens (monitoring, control and protection) are shared among different hierarchical levels, which are intelligent electronic devices (IEDs), substations automation units (SAUs) and a distribution management system (DMS).

Additionally, Commercial Aggregator Automation Systems (CAAS) are also included as agents in the IDE4L architecture and take the role of DR aggregators. In infra-hour time scales, the DR aggregator may receive flexibility activation requests from the DMS, which are target power values to be satisfied for a predefined period of time in a residential region.

Authors of [7] define a scalable method for the direct and explicit control of real-time nodal power injections/absorptions in order to provide local distribution networks (islanded and gridconnected microgrids) with the capability to quantify ancillary services to the upper power network, such as frequency control support and voltage compensation, thus targeting stringent realtime controls on sub-second time scales. Software agents defined in this method represent devices as well as subsystems, aggregating sections of the grid and a number of devices following a composable approach. Agents are pieces of software that are able to speak for and control a set of electrical systems with the aim to steer the state of the grid and its evolution towards a feasible state of operation. The final goal is to control the electrical state of the whole grid, which would be mainly competence of system operators as they possess both strong technical knowledge of such systems and a complete knowledge of the state and the topology of the grid. On the other hand, the approach described in this paper is a market-based software agent managed by a commercial DR aggregator, which pools flexibility from its customers' portfolio without including grid effects and without possessing knowledge of the status of the rest of the grid. It is market-based since the activation signals received by DR aggregators are the outcome of market clearing algorithms executed by market agents within DMS.

This paper assumes a two-layer communication-based control architecture for the management of individual consumers by the aggregator. The lower layer is located within each consumer's building where an energy management system (EMS) is installed to locally optimize operation of controllable devices. Upon request, such EMS sends the baseline and flexibility availability to the aggregator several minutes before each activation starts so that the aggregator can use this information to fairly allocate power setpoints depending on the size of the flexible demand that each customer has.

The upper layer does not manage individual devices within each consumer's building, but just its point of common coupling. In this layer, an aggregator's central manager has direct control on individual consumers and is able to online correct the aggregated power consumption by reallocating individual target flexibilities from consumers with unacceptable delivery performance to others with acceptable output. This approach is different from the one proposed in [10], where local communications between neighboring EMSs are involved instead of links between each EMS and the central manager.

The flexibility activation scheme assumed in this work is prorata based due to its simplicity. In this method, curtailment is allocated proportionally to customers' volume availabilities. This approach is inspired by the activation of automatic Frequency Restoration Reserves carried out by most European TSOs [11], although both activations pursue different goals.

Furthermore, under the assumption of increasingly enhancement of ICT applied to the distribution system, authors propose the implementation of real-time correction measures to counteract the under or over performance of customers in aggregators' portfolios. Nonetheless, these correction measures rely on the technical capabilities of smart metering devices as well as automation 
systems at customers' premises that are able to interact with aggregators.

The paper contributes the detailed implementation of two setups that emulate an aggregator and its interactions with the DSO and its customers' portfolio during flexibility activation events. The selected application is a short-term congestion management scheme to tackle constraints in distribution networks, following directions given in [4]. In the proposed test case, an unexpected congestion in a MV line occurs and the load curtailment of aggregated residential loads connected downstream of a nearby bus contributes to its removal. The grid model used is the same as in [12]. Results of the emulations carried out in the scope of the FP7 European project IDE4L are presented, highlighting the effects of the participation of DERs and microgrids to the congestion management outcome.

\section{Description of methodology}

\subsection{Assumptions}

The methodology described here is related to the flexibility procurement and activation processes dealt with by DSOs on one hand, and the bidding and allocation processes carried out by aggregators on the other hand. However, focus is made on flexibility activation and allocation stages. This methodology is based on [12].

DSOs are proposed to procure flexibility reserves, mainly through long-term contracts, in order to optionally activate them to provide ancillary services to the power system such as balancing or congestion management.

DSOs call upon flexible MV or LV (aggregated) network users to satisfy the activation of certain load or generation curtailment for a period of time. Typical means for flexibility activation include bilateral contracts between DSOs and flexible resources, as well as call for tenders or local markets organized by the DSOs.

In the bidding process, aggregators are assumed to build up upwards and downwards bids as the summation of the available volumes declared in advance by their customers portfolio. As will be detailed later, energy management systems (EMSs) programmed in customer automation systems enable this functionality.

Furthermore, in real-time basis, the status of individual flexibility volume availabilities may also be updated, thus providing a more reliable forecast than the one in the bidding event as it takes place closer to the activation period.

In case aggregators match their bids either totally or partially in the market clearing solution carried out by the DSO, they must turn matched volumes into individual customer setpoints in the so-called allocation process. It is proposed that such setpoints be allocated on a pro-rata basis as follows. The ratio of individual volumes to the aggregated one is kept the same for both the status update and allocation routines carried out by aggregators. For instance, if one customer has $1 \mathrm{~kW}$ of available volume (out of $100 \mathrm{~kW}$ of total aggregated volume in the customer base), but only $50 \mathrm{~kW}$ are activated, then the setpoint to this customer will correspond to a $0.5 \mathrm{~kW}$ curtailment.

During activation, non-performing customers, i.e. consumers or generators actually delivering more or less flexibility than expected in their connection points to the grid, prevent aggregators from reaching the targeted volume. Re-allocation events during activation periods are proposed as a means to reduce the impact of individual shortfalls in load in real-time basis. The proposed method consists of temporarily removing non-performing customers from eligible customers portfolio for the remaining activation period once bad performance has been detected. More details on the flexibility reallocation method are provided in [12].

The flexibility product or service is defined as an energy curtailment for a defined time interval. However, setpoints derived

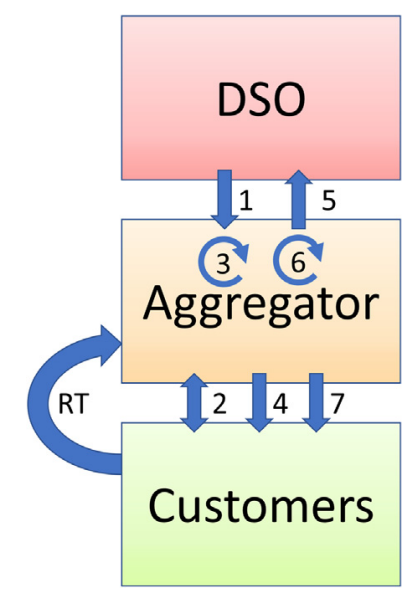

Fig. 2.1. Interactions between an aggregator and other parties in flexibility activation. Interactions are numbered according to chronologic occurrence. RT stands for real-time interactions.

from the pro-rata method consist of active power values. By time integrating smart meter readings, aggregators are able to assess actual energy performance in real-time and compare it against the corresponding fraction from the activated product. Hence, it is proposed that aggregators re-calculate the average power for the remaining period for its portfolio so that it compensates for energy mismatches cumulated since the activation start.

\subsection{Flexibility allocation and correction measures}

Flexibility activation and delivery involves the interactions between aggregators and DSOs on one hand, and aggregators and customers on the other hand, Fig. 2.1. The proposed scheme of flexibility activation from aggregated customers implies intensive coordination of customers' automation systems and aggregator systems, as customers provide feedback to aggregators on their operational status and local real-time measurements. Furthermore, since aggregators apply correction measures based on those measurements, more than one sending of setpoints occurs per activation period. On the other hand, DSO-aggregators interactions are less intensive since only one activation request and confirmation receipt is assumed per activation time interval.

The workflow of flexibility activation is as follows. On demand, the DSO requests certain flexibility volume to be provided by an aggregator at certain activation period, labeled 1 in Fig. 2.1. Then the aggregator requests an update of each individual customer operational status, i.e. the customer's baseline and up and downwards regulation band available for that period (label 2). Afterwards, the aggregator allocates the requested volume among its portfolio (label 3) and sends customers' setpoints (label 4). The aggregator also confirms the receipt of the order from the DSO (label 5).

The proposed scheme relies on measurements performed at customers' premises and an automation solution able to report them on real-time basis to the aggregator. Indeed, at certain time within the activation period, the aggregator performs two correction measures (label 6). First, it modifies the flexibility volume target for the remaining interval to counteract cumulated error in relation to expected output. Additionally, under-performing customers are disqualified for the remaining interval and their flexibility fraction is transferred to performing ones in the socalled re-allocation process. Finally, modified setpoints are sent to customers in order to execute the aforementioned correction measures (label 7). 


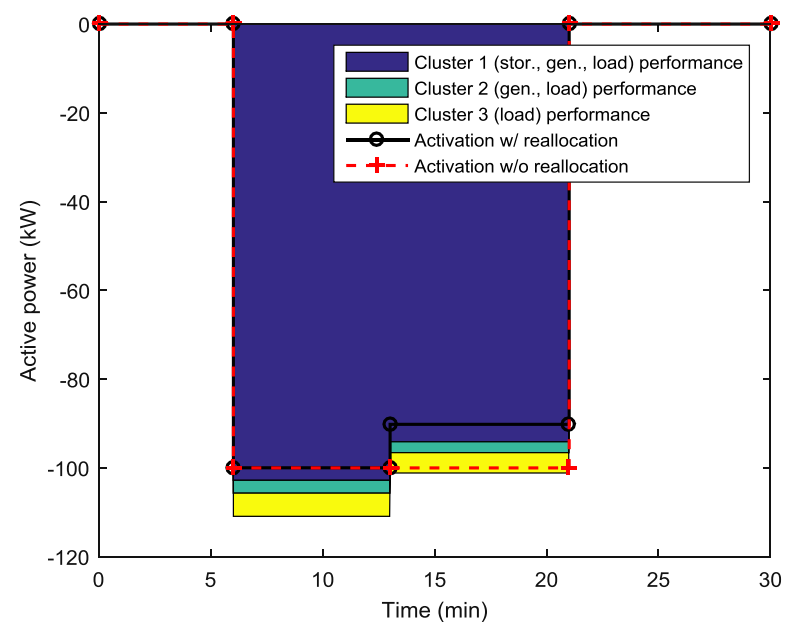

Fig. 2.2. Comparison between activation with and without flexibility reallocation as a correction measure to improve delivery performance. (For interpretation of the references to color in this figure legend, the reader is referred to the web version of this article.)

The impact of the correction measures is illustrated in Fig. 2.2. In this example, customers within the aggregator's portfolio are clustered in three groups according to the different devices connected at their premises: consumers with generation and storage (cluster 1 , blue area), consumers with generation (cluster 2, green area) and consumers without generation nor storage (cluster 3, yellow area). Globally, customers over-perform as their output is greater than the activation order of $-100 \mathrm{~kW}$ load curtailment (red dashed line). At minute 13, re-allocation takes place and a lower target volume is obtained so that over-performance in the first half of the activation period is counteracted during the second half.

\subsection{Customer operational status request}

Customers within aggregator's portfolio have local automation systems which enable users improve their energy usage. To this aim, EMSs programmed in customer's controllers able to forecast load profiles in advance are assumed. The forecasted power profile in the interconnection point of each customer premises is used by the aggregator to build up the baseline for each activation period.

EMSs are also proposed to send current customers' flexibility statuses according to their energy schedules. In this paper, a methodology to calculate flexibility availabilities from stationary battery energy storage systems within microgrids is developed.

Battery energy storage systems are composed of the battery and the AC/DC converter. In this methodology, active power losses of the converter are assumed constant within the operating range of the system and are included in the baseline profile of the microgrid. Accordingly, the flexibility availability from the battery is calculated at the DC side of the converter, without including the efficiency of the converter since it is already taken into account separately in the baseline.

This methodology is composed of four steps. Power injections are negative whereas power withdrawals are positive:

- Calculation of initial SOC at activation start

Since the status is reported minutes in advance of the activation start, the program takes into account changes in the SOC occurring during the pre-activation period

$\operatorname{SOC}_{I, \Delta_{t}}=\operatorname{SOC}_{I, \Delta_{t 0}}+\frac{\Delta_{t 0} \cdot p_{\Delta_{t 0}}^{B}}{N}$

- Calculation of battery power regulation band
The battery regulation band is limited by the maximum instantaneous power for the battery

$d_{\Delta_{t}}^{B, c}=\min \left(\frac{\left(\overline{S O C}-S O C_{I, \Delta_{t}}\right) \cdot N}{\Delta_{t}}, \bar{P}^{B}\right)$
$d_{\Delta_{t}}^{B, d}=\max \left(\frac{\left(S O C-S O C_{I, \Delta_{t}}\right) \cdot N}{\Delta_{t}}, \underline{P}^{B}\right)$

- Calculation of interconnection power regulation band

Similarly, the interconnection regulation band is limited by the grid tie capacity.

$d_{\Delta_{t}}^{I, p}=\min \left(d_{\Delta_{t}}^{B, c}-p_{\Delta_{t}}^{B}, \bar{P}^{I}-p_{\Delta_{t}}^{I}\right)$

$d_{\Delta_{t}}^{I, s}=\max \left(d_{\Delta_{t}}^{B, d}-p_{\Delta_{t}}^{B}, \underline{P}^{I}-p_{\Delta_{t}}^{I}\right)$

- Reduction of interconnection power regulation band

All previous calculations are based on estimations that are subject to stochasticity. Aiming at reducing the impact of uncertainty on the actual flexibility delivery, a factor is used that further reduces the band

$d_{\Delta_{t}}^{I, p, r}=d_{\Delta_{t}}^{I, p} \cdot K^{p} \quad 0 \leq K^{p} \leq 1$

$d_{\Delta_{t}}^{I, s, r}=d_{\Delta_{t}}^{I, s} \cdot K^{s} \quad 0 \leq K^{s} \leq 1$.

The values of $K^{p}$ and $K^{s}$ factors can be tuned according to the reliability of the forecasts used in the methodology. Values close to zero make the system more conservative whereas values approaching unity make it less conservative.

Active power setpoints received by local automation systems from aggregators' systems will override the load profile programmed by the EMS for the customer interconnection point. Once activation periods elapse, EMSs take control over the interconnection profile at local facilities again.

The method proposed for the calculation of the customer's baseline and available flexibility is illustrated with an example depicted in Fig. 2.3. The aggregator is requesting this customer an estimation of the status from the next four minutes on. The EMS has already scheduled $-2 \mathrm{~kW}$ of battery discharging for customer's self-consumption (supplying critical load and battery converter losses). Hence, the baseline is zero in this case since no power is exchanged at the interconnection point (red line). Regarding flexibility, the interconnection capacity $\bar{P}^{I}-p_{\Delta_{t}}^{I}=6.6 \mathrm{~kW}$ is the constraint used for the calculation of upwards flexibility since it is more restrictive than the available battery power $d_{\Delta_{t}}^{B, c}-p_{\Delta_{t}}^{B}=$ $6.7 \mathrm{~kW}$ (3.1). A factor $K^{p}$ of 0.75 has been applied. On the other hand, the available battery power $d_{\Delta_{t}}^{B, d}-p_{\Delta_{t}}^{B}=-3.3 \mathrm{~kW}$ is more restrictive in the downwards flexibility case compared to the interconnection limits $P^{I}-p_{\Delta_{t}}^{I}=-6.6 \mathrm{~kW}(3.2)$, since this storage device is already scheduled at a discharging power thus limiting the additional volume that can be delivered.

\section{Description of setup}

\subsection{Emulation of aggregator's premises}

For the real-time simulation setup, the Real Time Digital Simulator (RTDS) has been used. The power system of UNARETI, a DSO operating in Italy, has been modeled (both LV and MV) in 4 racks of RTDS, respectively 1 rack for LV (where some customers and generators have been merged in order to save computational power) and 3 racks for the MV grid, which has been modeled one to one with respect to the actual grid. 


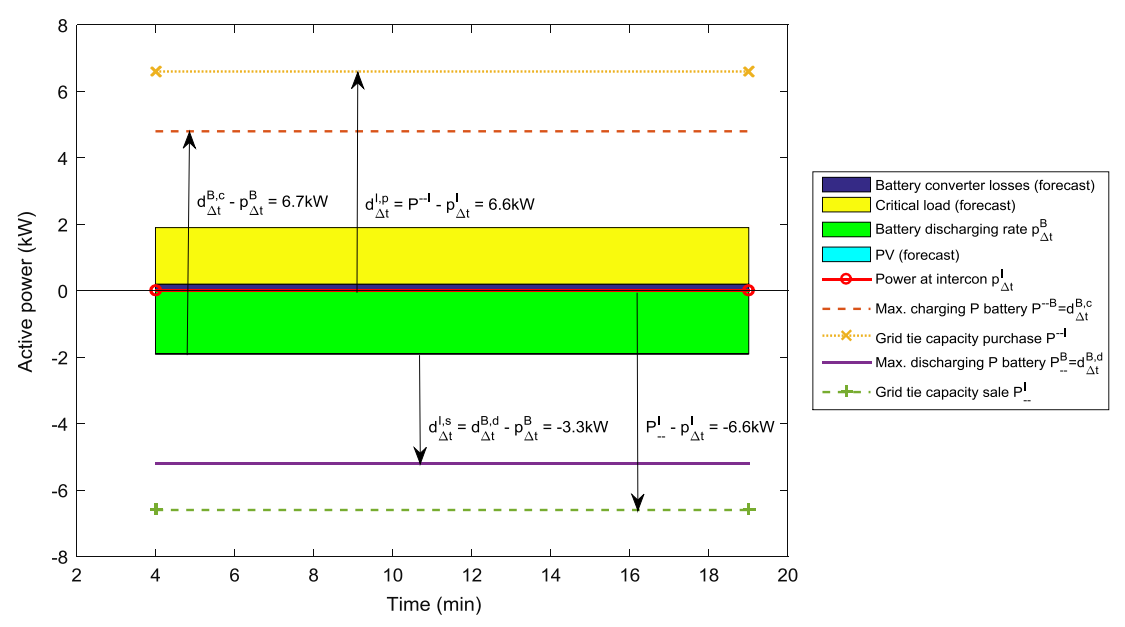

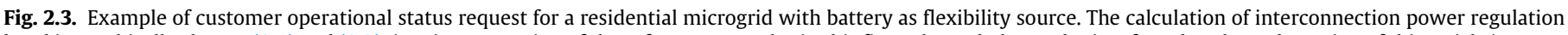
band is graphically shown, (3.1) and (3.2). (For interpretation of the references to color in this figure legend, the reader is referred to the web version of this article.)

Thanks to this configuration it was possible to accurately simulate the power system, and test the real-time CA algorithms, together with other functions and services developed and implemented in the IDE4L project. Control signals can be delivered to controllers, such as simulated inverters or intelligent electronic devices, in the simulation environment in RTDS with industrial protocols, through emulated communication infrastructure, hence investing also the effects of delays.

The communication between the RTDS simulator and the remote computer is built using the DNP3 protocol available through the GT-NET card of the RTDS simulator and a dedicated OPC server installed on a remote machine, where the Matlab algorithm the Commercial Aggregator is performed. The OPC server, implemented using Kepware Kepserver, enables the creation of a channel between the real-time simulator and Matlab, which uses its own OPC toolbox for interfacing with such server, thus enabling the exchange of analogue and digital inputs and outputs. These data represent the measurements coming from the simulated grid, such as power and voltage measurements, and the control setpoints sent from the CA to its customers. The complete schema of the test platform is depicted Fig. 3.1.

The Market Agent, which is part of the Tertiary Controller of the DSO, has been developed in the context of the IDE4L project and is further described in [13]. The MA collects data from the simulation regarding power and voltages in the MV network, checks if there is a congestion and, in case it detects a congestion, runs an Optimal Power Flow algorithm to find the amount of flexibility needed to resolve it [14].

Then, the needed flexibility is calculated and this value is saved into a local file that is later read by the CA. The Commercial Aggregator receives the flexibility product, called Conditional ReProfiling (CRP) activation request and the amount of flexibility required and then starts its allocation algorithm (see Fig. 3.2).

The CA, when receiving a CRP activation request, enters in the main loop for the flexibility allocation. During this loop, that lasts $15 \mathrm{~min}$, there is a continuous exchange of data from and to the real-time simulator, in order to acquire the data regarding the actual status of the LV grid and to send the control setpoints to the customers to allocate the flexibility, check whether the controls have been received and executed by the customers and eventually recalculate the setpoints according to the real participation of the users.

\subsection{Emulation of customer's premises}

The microgrid simulation setup aims at testing particular parts of the electrical process management in customer premises during flexibility activations. The electrical process management in the setup includes:

- Energy transformations and directly involved physical equipment

- Equipment used to control and monitor the physical equipment both locally and centrally

- Central EMS that operates customer's premises at all times, also including flexibility activation periods.

The EMS is capable to manage customer's devices in two execution modules. The first one, called Central Controller, is an energy planner that minimizes customer's operational costs on daily basis as described in [15]. The second one, called Local Controller, manages deviations from the schedule obtained by the Central Controller, caused by forecast errors and abnormal operation of controllable devices. The aim of this last module is to minimize the impact of real-time power imbalances on the scheduled interconnection profile.

The architecture not only considers the implementation of onecustomer premises but also the co-simulation of the interactions of an aggregator with its customers' portfolio:

- Local measurement readings (label RT in Fig. 2.1)

- Customers' flexibility statuses (label 2 in Fig. 2.1).

The flexibility allocation and correction measures methodology performed by one aggregator are also simulated in the setup.

The architecture is depicted in Fig. 3.3. Power components comprise one industrial real second life Lithium-ion battery system and two custom-made emulators described in [16]. The battery system includes a TQMA-28-AA (2xEthernet and 2xCAN) control board and the emulators comprise MYD-AM335X (2xEthernet and $1 \times C A N$ ) development boards (all of them are named local concentrators in the setup). Two Ethernet switches are used, one for the microgrid operation layer of the premises, and the other for a configuration layer needed by the emulators to set their emulation active power profiles. Two Windows-based OS desktop computers run the central EMS on one hand and the aggregator's flexibility allocation algorithm on the other hand. Additionally, one Linux-based OS computer runs the central data concentrator of the physical equipment, called central concentrator.

Communications between the local and central concentrators in both configuration and operation networks are Modbus over TCPIP, whereas communications in the operation network are socket TCP-IP for the EMS and its related data exchange with the central concentrator and the aggregator, respectively. CAN bus is used 


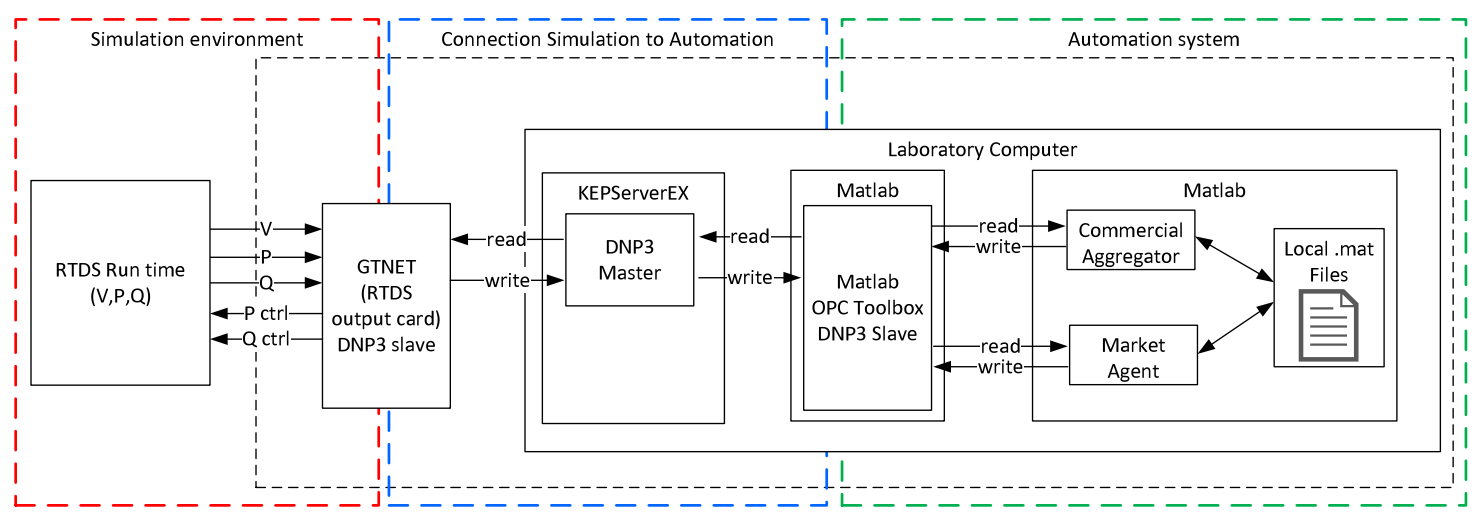

Fig. 3.1. Test platform implementation.

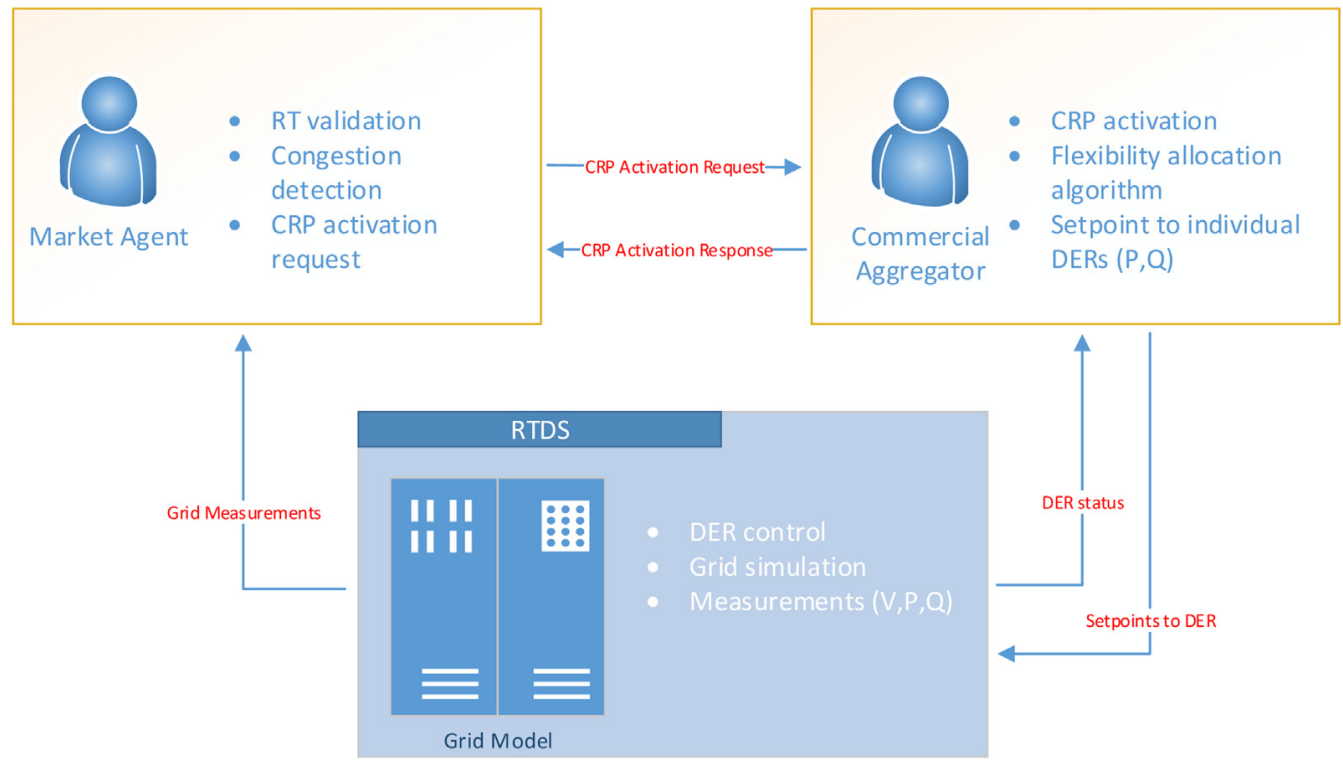

Fig. 3.2. Simulation schema.

Table 4.1

First flexibility allocation data.

\begin{tabular}{|c|c|c|c|c|c|c|}
\hline Case number & $\begin{array}{l}\text { Initial available } \\
\text { flexibility }(\mathrm{kW})\end{array}$ & $\begin{array}{l}\text { Requested Flexibility } \\
\text { 1st allocation (kW) }\end{array}$ & $\begin{array}{l}\text { Activated Flexibility } \\
\text { 1st allocation (kW) }\end{array}$ & $\begin{array}{l}\text { Percentage of } \\
\text { available flexibility } \\
\text { requested (\%) }\end{array}$ & $\begin{array}{l}\text { Percentage of } \\
\text { requested flexibility } \\
\text { activated (\%) }\end{array}$ & $\begin{array}{l}\text { Percentage of } \\
\text { performing } \\
\text { customers (\%) }\end{array}$ \\
\hline 1.a & 56.38 & 39.84 & 39.84 & 70.66 & 100.00 & 81.82 \\
\hline 4.a & 56.38 & 39.84 & 39.84 & 70.66 & 100.00 & 39.39 \\
\hline 1.b & 56.38 & 39.84 & 39.84 & 70.66 & 100.00 & 81.82 \\
\hline 2.b & 56.38 & 39.84 & 39.84 & 70.66 & 100.00 & 42.42 \\
\hline
\end{tabular}

in the communications between each power component and its corresponding local concentrator.

The functions implemented in the different computers of the setup are depicted in Fig. 3.4. Two Matlab scripts are run, one for the Flexibility Allocation algorithm and another for the generator of customers' response of the aggregator's portfolio. C++ language is used in the energy planner and energy balance algorithms within the EMS, as well as the microgrid configurator and central concentrator. Finally, local data concentrators are developed in C language.

The flexibility allocation algorithm reads MAT files as activation requests from the DSO, and CSV files as virtual customers statuses and energy measurements. On the other hand, this algorithm generates CSV files as virtual power setpoints. Information exchange between the microgrid's EMS and the aggregator's flexibility allocation is through XML files (status, energy measurements and power setpoints). The EMS is configured via one CSV file (load forecast) and XML files (microgrid configuration, energy prices, solar irradiation and ambient temperature forecasts). Commands and information exchanged between the EMS's energy balance and the central concentrator is through XML messages. Data exchanged between the central concentrator and the local data concentrators is through Modbus messages. Finally, CAN bus messages are used 


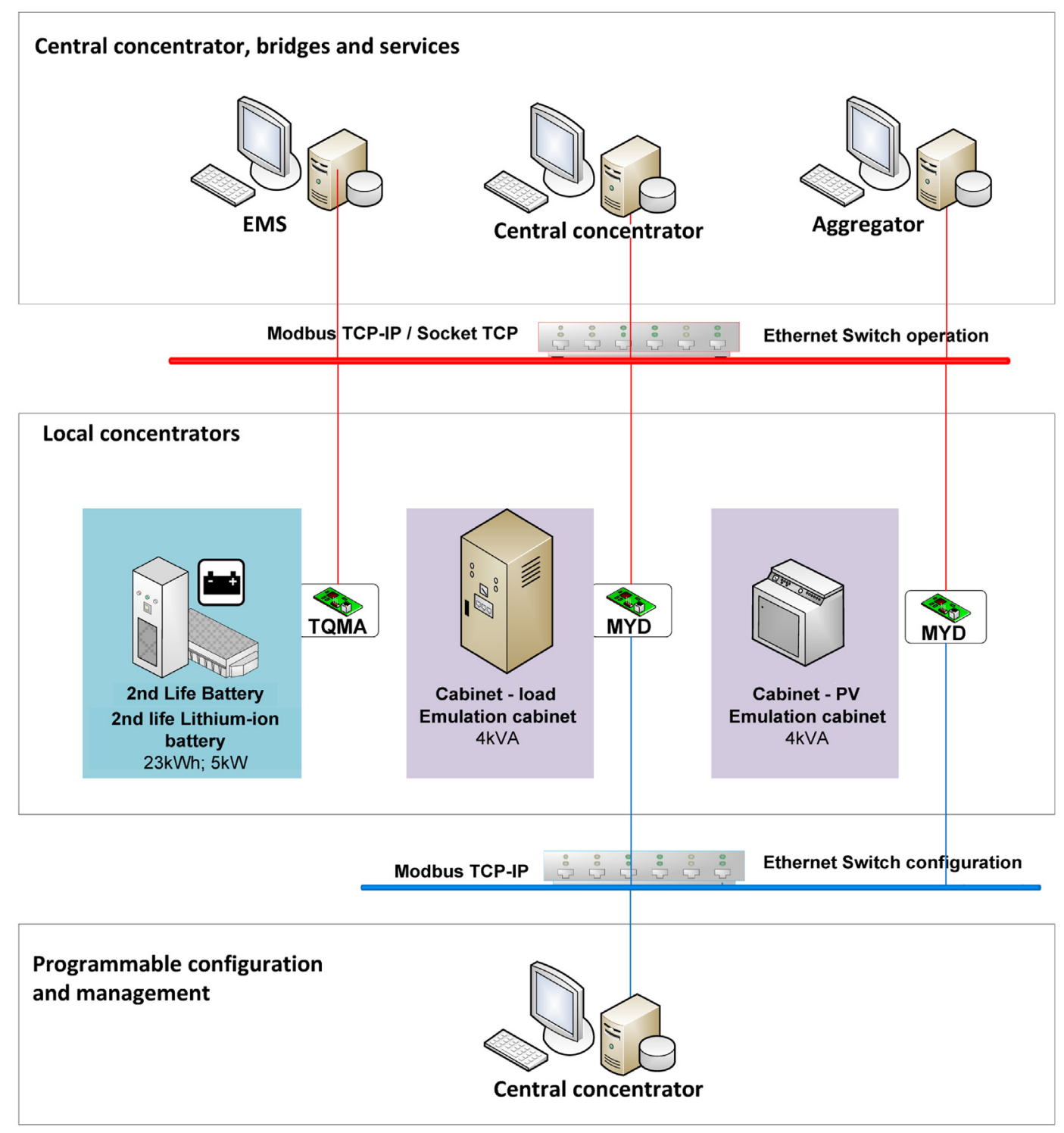

Fig. 3.3. Microgrid simulation architecture.

for information exchange between local concentrators and control devices within power components.

\section{Emulation results}

As already mentioned, two different testing setups have been implemented. Test configurations and results focusing on the aggregator's side are first discussed, whereas the ones on the customer's side are described later on.

\subsection{Aggregator's test configurations}

In this test configuration, the goals pursued were:

- Evaluate how the real-time execution of the CA algorithm could adapt to partial acceptance of proposed flexibility from the customers

- Evaluate the impact of different timing strategies on the performance of the CA algorithm

- Evaluate to which extent the Commercial Aggregator algorithm is robust in regards to communication delays.
The main advantage of the real-time execution, in fact, is that the algorithm can verify how the users react to the proposed commands and change the allocation strategy accordingly, in order to deliver, or at least try to deliver, the requested CRP products even if only a small group of customers participates to the flexibility allocation. Moreover, different configurations for the execution time of the CA have been tested. The aim was to evaluate how the different execution profiles affect the performance of the Aggregator and find which configuration gives the best results. For this purpose, four different timing configurations have been tested. The time period that has been modified is the Flexibility delivery check window (highlighted in red in Fig. 4.1). This is the elapsed time between two energy measurements requests sent to the customers. These two measurements are used to calculate the actual energy consumed by the customer during this time window and compare it with declared base energy consumption, expected if no flexibility is activated. To be considered as performing, a customer should execute the requested setpoint within a tolerance band of $\pm 20 \%$. To check whether the customer did behave as expected the energy readings are used to extract an average power consumption of the user during the considered time window. If a customer partially executes the setpoint, the wider the time window gets the more its 


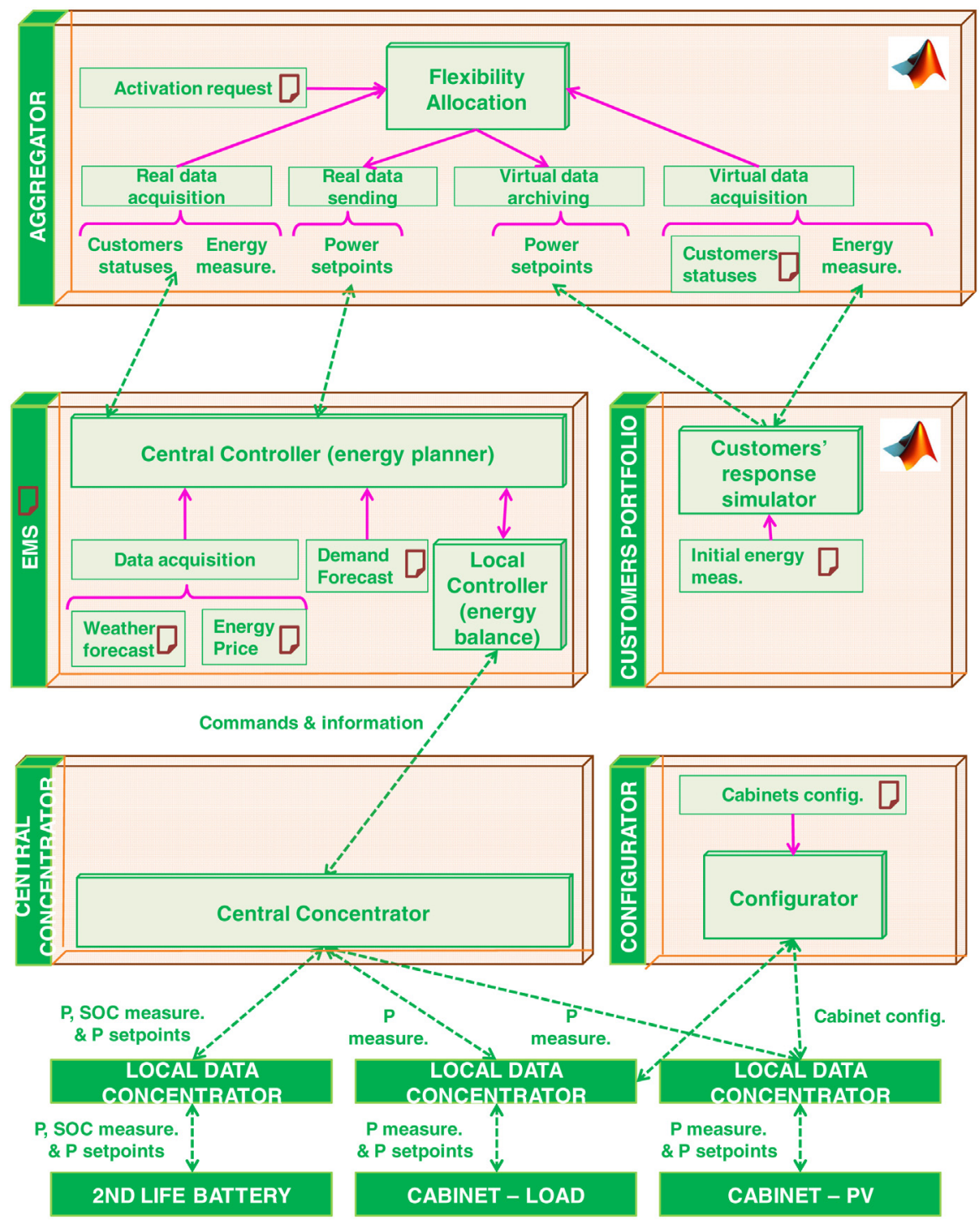

Fig. 3.4. Function layer for the emulation of customer's premises.

consumption diverges from the expected value and gets closer to the tolerance band border, even exceeding it. For this time window four cases have been considered:

- 3 min window (Case 1.a)

- 4 min window (Case 2.a)

- 5 min window (Case 3.a)

- 6 min window (Case 4.a).

Finally, in this implementation, the communication between the Aggregator and the customers can be delayed, thus affecting the time required to transmit the setpoints to the customers and to execute them. By doing this, it was possible to test the behavior of the Aggregator and evaluate its performance in presence of communication delays with the customers. In the first set of test no delay was present between the setpoint transmission from the CA and their execution by the customers (Cases 1.a, 2.a, 3.a, 4.a). In the second set of simulations (Cases 1.b, 2.b, 3.b, 4.b) a random delay, between few seconds and one minute, has been integrated for each customer. In this way, the execution of every setpoint is performed in a different time instant (highlighted in blue in Fig. 4.1).

For the power profiles needed for building the desired scenario, real data provided by the DSO, acquired during an entire year, have been used as basis for their generation. These data have been combined in order to create the profiles used for the simulation, for both the LV and MV. To create the congestions needed for the emulation of the CA the real data have been recombined and multiplied by different factors, thus obtaining the desired test conditions.

The base scenario is the same for all the different test, in order to allow the comparison of the results obtained. In the test scenario, a congestion of $102.02 \%$ is found in the line between buses 952 and 1056. The flexibility requested during the simulation was $39.84 \mathrm{~kW}$ during the 15 min' time window.

\subsection{Results at aggregator level}

Once the CRP activation request is received, the CA divides the total requested flexibility among its customers and, after 6 min from the start of the simulation, sends the first setpoints. Once the setpoints are sent the Flexibility delivery check window starts and the algorithm waits the required amount of time, identified by the case under test.

In Table 4.1 the results obtained at the end of such period are reported. At the first allocation, the amount of requested flexibility is the same for all cases and in all cases the CA was able to 


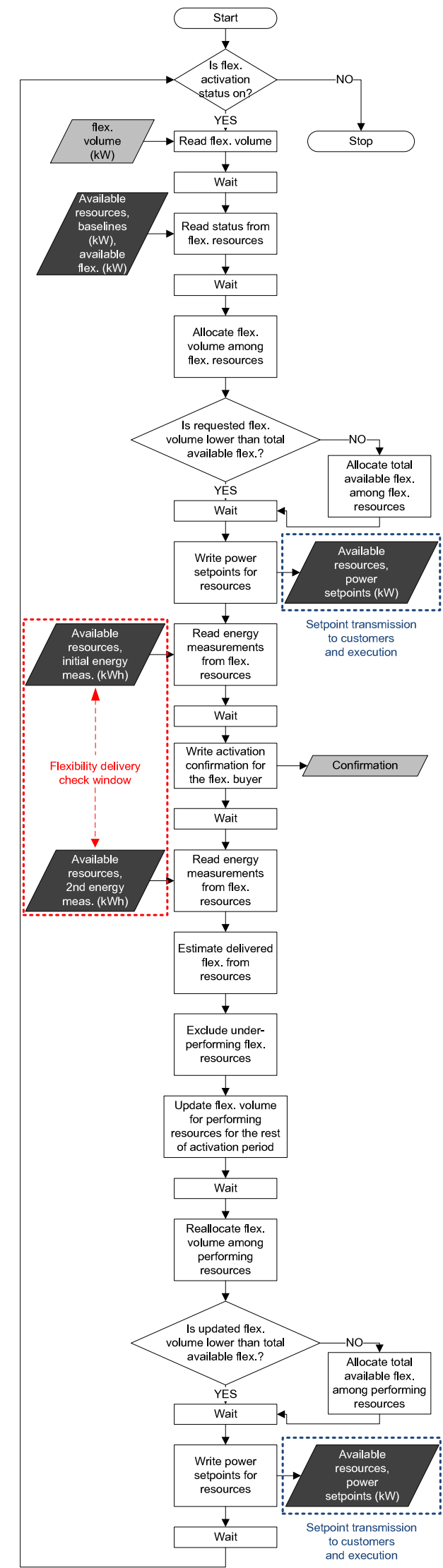

Fig. 4.1. Commercial aggregator algorithm execution workflow. (For interpretation of the references to color in this figure legend, the reader is referred to the web version of this article.)

Source: Adapted from [12]. allocate the flexibility among the customers. However, the actual delivered flexibility and thus the percentage of real performing users decreases when the delivery check window widens.

For this reason, the narrower the time window is the more users will be considered as performing, even if they are not exactly executing the requested setpoint. In fact, looking at the obtained results it can be noted that, even with the same behavior from the customers, the percentage of non-performing customer increases with wider windows.

In Fig. 4.2 the profile of both total consumed power for the bus and the activated flexibility for bus 1056 are reported. It can be noted that, when the first setpoint command is executed by the customers, the profile of the power consumption decreases accordingly.

The performance of the CA worsens in presence of delays. In fact, in case 2.b the percentage of performing users decreases with respect to case 2.a. This reflects in a lower available flexibility for the second period that, as reported in Table 4.2, is less than the required amount. Therefore, in case 2 . b the CA is not able to allocate all the requested flexibility even if it can be done in case 2.a, where no delays are present.

Since the customers did not respond as expected and some of them did not participate to the CRP activation as requested from the CA, the CA recalculates the setpoints for the rest of the 15 min' time window, taking into account the real participation of the customers to the flexibility and discarding those who did not execute the requested commands, thus updating the total available flexibility volume and the list of active customers.

The reallocation of the flexibility at this stage takes into account not only the original amount, but also the flexibility not delivered during the first part of the allocation.

This leads to the new flexibility allocation and setpoint transmission, as reported in Table 4.2. The updated available flexibility value decreases for all cases, however in cases 1.a and 2.a its value is still enough to allocate all the needed flexibility for the remaining period of the 15 min' window.

For cases 3.a and 4.b the remaining flexibility is less than the required amount and even if the CA allocates all the available flexibility it will not be able to provide the total amount of flexibility requested in the first place.

When delays are introduced the only configuration that allows the complete allocation of flexibility is the one used in case 1.b, while in all other configurations the available flexibility is lower than the needed one.

Once the allocation is done the CA sends new setpoints to the customers who are actually participating to the CRP activation, thus obtaining a new change in the power profile of the bus, as shown in Fig. 4.2 from minute 9 of the simulations. For the remaining part of the allocation window the involved customers participate to the flexibility, until the end of the $15 \mathrm{~min}$ ' time window.

In the meantime, the original congestion is solved, hence no more CRP products are needed. The CA continues to deliver the CRP until the desired duration of 15 min has been reached and then send the final command stopping the flexibility delivery, around minute 24 .

In Table 4.3 the total amount of energy reduction is reported for all test cases. It can be noted that in both cases 1.a and 1.b, the ones with a 3 min wide delivery check window, the CA was able to deliver a high share of the requested flexibility, remaining inside the $\pm 20 \%$ tolerance range.

The 4 min wide check window (cases 2.a and 2.b) provides results within the tolerance band only when no delays are present, while in presence of delays the performance decreases too much. 

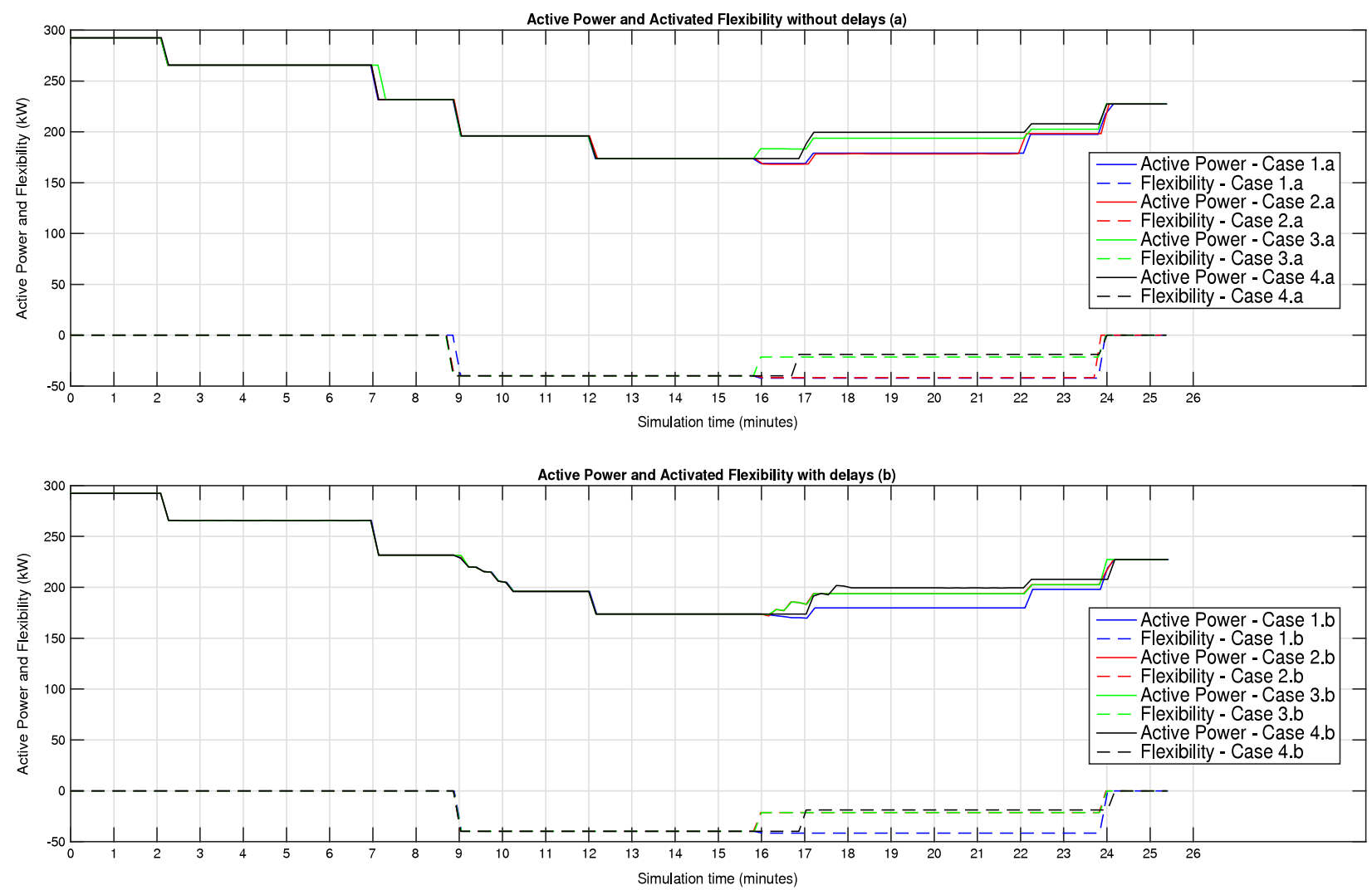

Fig. 4.2. Bus active power and activated flexibility profiles for different test cases.

Table 4.2

Second flexibility allocation data.

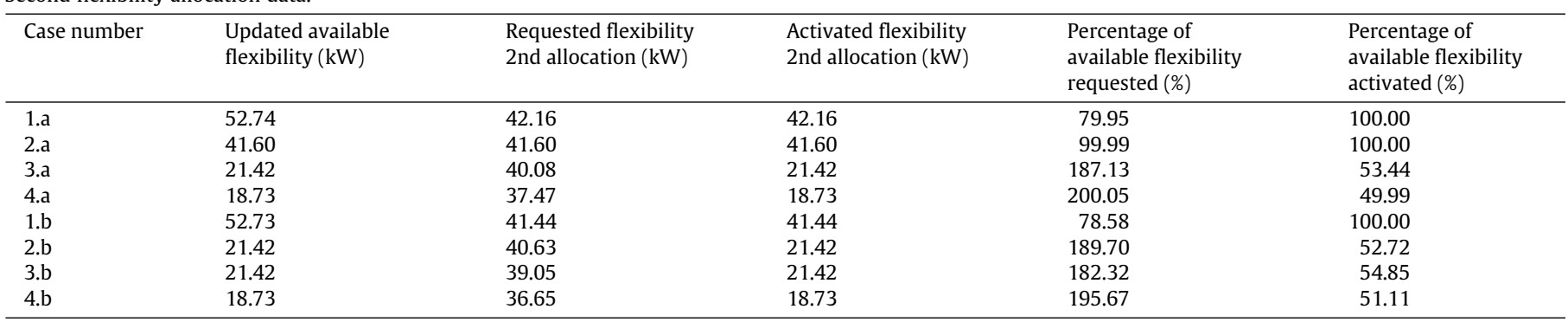

Table 4.3

Energy reduction goal and actual obtained reduction.

\begin{tabular}{llll}
\hline Case number & Total energy requested $(\mathrm{kWh})$ & Total Energy provided $(\mathrm{kWh})$ & Percentage of provided energy $(\%)$ \\
\hline 1.a & 9.96 & 9.15 & 91.8946 \\
2.a & 9.96 & 8.89 & 89.2761 \\
3.a & 9.96 & 6.77 & 68.0151 \\
4.a & 9.96 & 6.24 & 62.6054 \\
1.b & 9.96 & 8.53 & 85.6325 \\
2.b & 9.96 & 7.09 & 71.1536 \\
3.b & 9.96 & 7.09 & 71.2219 \\
4.b & 9.96 & 5.93 & 59.5823 \\
\hline
\end{tabular}

In Fig. 4.3 the profiles of the active power in the bus and the activated flexibility for cases 1.a and 1.b are reported. It can be noted how the delays affect the execution of the setpoints and thus the profile of the activated flexibility. However, the amount of activated flexibility, after the delays, is still the one requested by the CA. The effect of delays is present even the second setpoints execution, as can be seen in Fig. 4.4.

The main effect of delays is however on the total energy reduction obtained, that is lower in the case with delays.

\subsection{Customer's test configuration}

The activation of one 15-minute period is simulated at customer's facilities. The timeline of the test is as follows. The activation request starts at 19:00 and 2 min later the aggregator requests statuses from its customers' portfolio (19:02). Then, flexibility is allocated 2 min later (19:04) and afterwards setpoints are sent. The delivery starts at 19:06. In the second part of the activation interval, first re-allocation process takes place at 19:11 and the resulting modified setpoints are sent and immediately applied at 


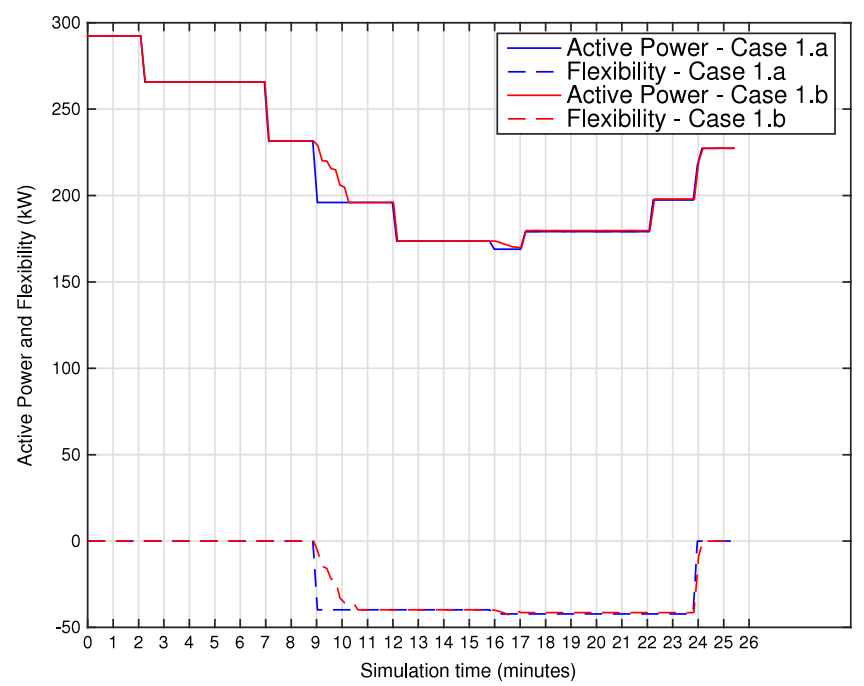

Fig. 4.3. Bus active power and activated flexibility profiles in test case 1 , with and without delays.

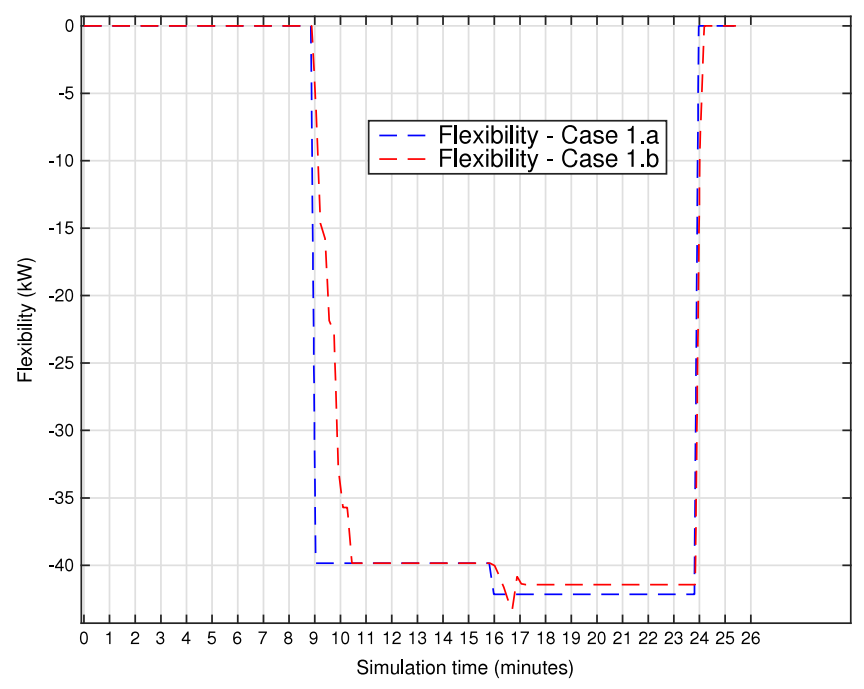

Fig. 4.4. Delivered flexibility profiles in test cases with and without delays.

19:13. Finally, flexibility delivery stops 15 min after delivery start (19:21) since no more activations are requested by the DSO.

Input data and configuration details of the different functions shown in Fig. 3.4 are summarized in Table 4.4. 173 available customers are simulated in the aggregator's portfolio, clustered in three groups as in Fig. 2.2. Flexibility sources of cluster 1 are batteries and controllable heat pumps, whereas only adjustable heat pumps provide flexibility in clusters 2 and 3 . Histograms of the customers' operational statuses are shown in Fig. 4.5. It is observed that customers in cluster 1 provide much more flexibility to the system (both upwards and downwards directions) since they add power modulation from batteries to the heat pumps regulation, which are common to all clusters. On the other hand, clusters 2 and 3 have similar available volumes because they share the same flexibility source (heat pump).

Virtual customers' delivery performance is simply simulated with two files containing individual energy measurements in two different time instants. The first file contains virtual meter readings at the delivery start (19:06) and is an input for the test. The customers' response simulator generates the second file by adding uniformly distributed random load curtailments between $75 \%$ and
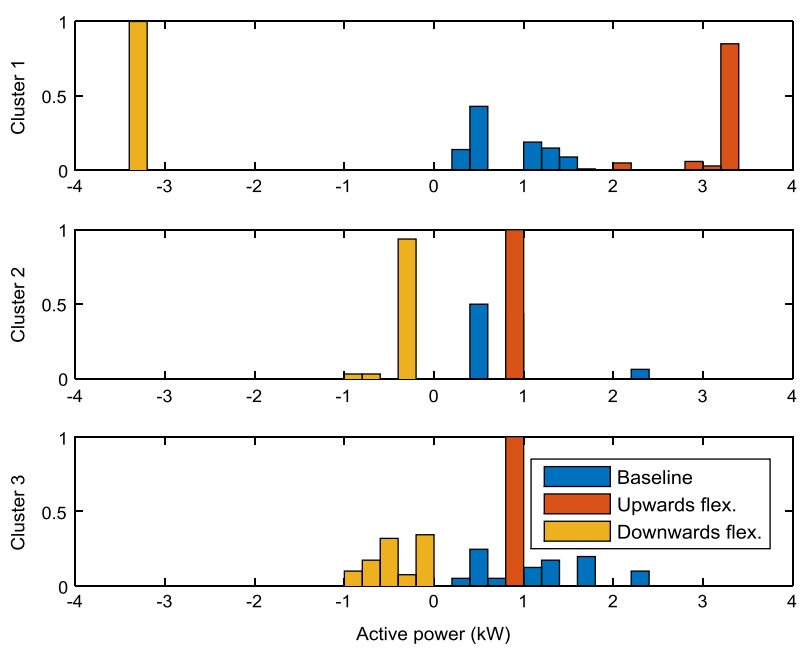

Fig. 4.5. Histograms of virtual customers' statuses. Bins are of 0.2-kW size. Relative frequencies are depicted in the $y$-axis.

$144 \%$ of targeted values resulting from setpoints obtained in the first allocation.

Regarding the customer emulated in the test (residential microgrid), it is assumed belonging to cluster 1 , and includes a second life battery and a PV unit as storage and generation devices. In this particular setup, the second life battery is connected to the microgrid through an AC/DC converter that has estimated active power losses of $0.2 \mathrm{~kW}$ in the operational range of the test. Such losses are not measured by the battery system control scheme, thus producing a systematic error. The EMS takes into account this additional load in the energy planner and energy balance in order to overcome mismatches between battery power commands and measurements at the AC side of the converter.

\subsection{Results at customer level}

During the test, power analyzers were used to measure active power in the AC side of the battery system and the two emulators' terminals, Fig. 4.6. Initially, the EMS schedules $-1.6 \mathrm{~kW}$ discharge power to self-consume the critical residential load of $1.6 \mathrm{~kW}$. Then the battery output falls down to $-2.4 \mathrm{~kW}$ since the EMS receives a setpoint of $-0.8 \mathrm{~kW}$ at the interconnection. The second part of the activation period the setpoint is modified to $-0.7 \mathrm{~kW}$ because of the re-allocation process carried out by the aggregator. Finally, when activation ends the EMS resumes operation without constraints imposed by remote control.

\subsection{Overall results discussion}

The emulation results at aggregator level showed how the performances are dependent on the flexibility window settings. Longer flexibility check windows have proved to be unable to provide the requested amount of flexibility, while the narrower one was able to deliver the requested flexibility even in presence of delays.

The effect of delays on the execution of the setpoints has been a general deterioration of performances. In case 2.b it caused a drop of performance severe enough to prevent a successful flexibility delivery during the whole 15 min time window.

Finally, the technical feasibility and functionality of a setup including a real battery energy storage system which emulates the premises of a single customer participating in the proposed scheme has been demonstrated. On one hand, active power measurements have revealed successful power exchanges at the point of common 
Table 4.4

Configuration for the emulation of customer's premises.

\begin{tabular}{|c|c|}
\hline Function of input file & Data \\
\hline Flexibility activation timeline & $\begin{array}{l}\text { 1: Activation request (19:00), } 2 \text { : status request (19:02), } 3 \text { : flexibility } \\
\text { allocation (19:04), } 4 \text { : sending of setpoints (19:06), 5: activation } \\
\text { confirmation (19:07), } 6: \text { flexibility re-allocation (19:11), } 7: \text { sending of } \\
\text { modified setpoints (19:13) }\end{array}$ \\
\hline Flexibility allocation (configuration) & $\Delta_{t 0}=4 \mathrm{~min}, \Delta_{t}=15 \mathrm{~min}$ \\
\hline Activation request (volume) & $-100 \mathrm{~kW}$ \\
\hline Virtual customers' statuses & Fig. 4.5 \\
\hline Customers' response simul. & $\begin{array}{l}\text { Uniformly distributed random curtailed load values between } 75 \% \text { and } \\
144 \% \text { of target }\end{array}$ \\
\hline Initial energy measurements & $1000 \mathrm{kWh}$ \\
\hline Initial time EMS execution & 19:00:00 UTC (Windows OS time) \\
\hline EMS configuration & $\begin{array}{l}\text { Interconnection: bi-directional } \bar{P}^{I}=6.6 \mathrm{~kW} \underline{P}^{I}=-6.6 \mathrm{~kW} \text { 2nd life } \\
\text { battery: } N=23 \mathrm{kWh} \overline{S O C}=95 \% \underline{S O C}=15 \% \bar{P}^{B}=5 \mathrm{~kW} \underline{P}^{B}=-5 \mathrm{~kW} \\
\text { Battery converter losses: } 0.2 \mathrm{~kW} \\
\text { PV unit maximum power: } 1.5 \mathrm{~kW}\end{array}$ \\
\hline Energy planner & $\begin{array}{l}\text { Optimization algorithm: execution every } 1 \mathrm{~min} \text {, step resolution } 15 \\
\text { min, number of steps in horizon } 96\end{array}$ \\
\hline Energy balance & $\begin{array}{l}\text { Energy balance algorithm: execution every } 3 \mathrm{~s} \text {, refresh connection } \\
\text { with central concentrator every } 3 \mathrm{~s}\end{array}$ \\
\hline Weather forecast data (EMS) and power profile config. (PV cabinet) & $\begin{array}{l}\text { Ambient temperature and solar irradiation extracted from ARPA } \\
\text { Lombardia (Lombardy region) data base [17] }\end{array}$ \\
\hline Energy price data & $\begin{array}{l}\text { Day-ahead market prices extracted from Italian electricity market } \\
\text { operator GME [18] }\end{array}$ \\
\hline Demand forecast (EMS) and power profile config. (load cabinet) & $\begin{array}{l}\text { Adapted from active power meter readings from one real customer } \\
\text { with PV generation (FP7 IDäL project) }\end{array}$ \\
\hline
\end{tabular}

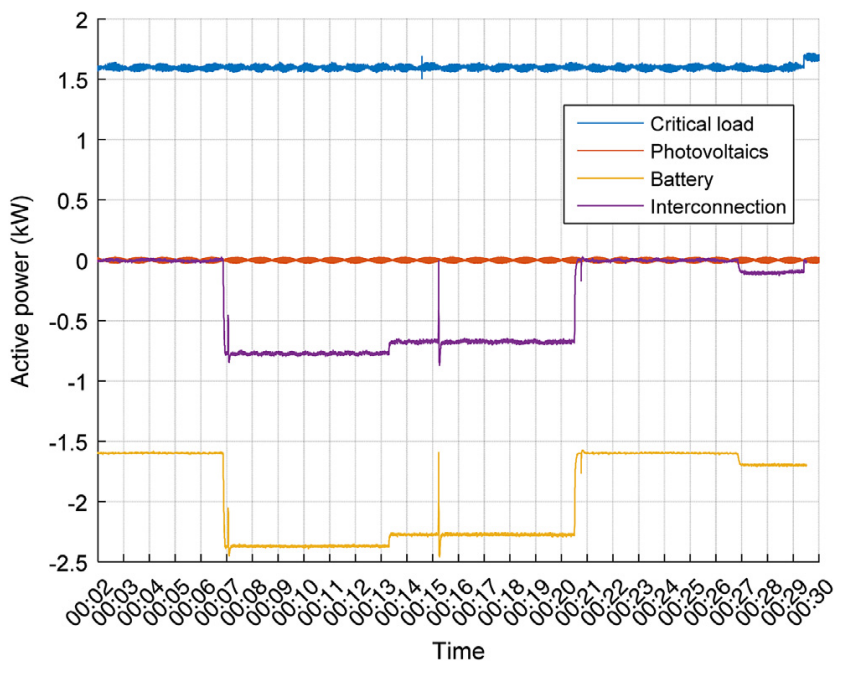

Fig. 4.6. Active power measurements during flexibility delivery at customer's premises.

coupling of the customer's installation. On the other hand, the functionality of the customer's EMS to estimate current customers' flexibility status according to its energy schedules and battery SOC has also been successfully tested.

\section{Conclusions}

From customer's perspective, a methodology has been proposed that coordinates automation systems located at customers' premises with aggregator's systems operation in real-time. In particular, a flexibility activation and delivery workflow has been tested in which individual customers report current operational status to the aggregator, so that flexibility allocation can be done based on updated and particularized volume forecasts. This methodology fits well with customers managing automation systems, which generate energy schedules ex-ante such as energy planners with optimization algorithms.
The tests carried out with different activation and delivery workflows allowed to assess the effect of different timing settings of the algorithm. The results showed how a narrower time window for the flexibility activation check helps in achieving better performance, since the Aggregator is able to correct the setpoints before misbehaving customers cause a difference between the desired flexibility and the real activated one so big that the request in term of flexibility reallocation in the second period would be too high for the customers and thus not achievable.

Finally, the simulations with the introduction of communication delays proved how the algorithm is robust, being is still able to deliver the requested flexibility with a degradation of the overall performance that is however inside the allowed tolerance range.

\section{Acknowledgment}

The research leading to these results has received funding from the European Union's Seventh Framework Programme (FP7/20072013) under grant agreement $n^{\circ} 608860$.

\section{References}

[1] Directive 2012/27/EU of the European Parliament and of the Council of 25 October 2012 on energy efficiency, amending Directives 2009/125/EC and 2010/30/EU and repealing Directives 2004/8/EC and 2006/32/EC Text with EEA relevance, (Available Online at: http://data.europa.eu/eli/dir/2012/27/oj).

[2] P. Bertoldi, P. Zancanella, B. Boza-Kiss, Demand Response status in EU Member States, EUR 27998 EN; http://dx.doi.org/10.2790/962868.

[3] V. Rious, Y. Perez, F. Roques, Which electricity market design to encourage the development of demand response? Econ. Anal. Policy 48 (2015) 128-138.

[4] Smart Grid Task Force-Expert Group 3, Regulatory Recommendations for the Deployment of Flexibility, July 2015 (Available Online at: http://ec.europa. eu/energy/sites/ener/files/documents/EG3\%20Final\%20-\%20January\%202015. pdf).

[5] L. Gkatzikis, I. Koutsopoulos, T. Salonidis, The role of aggregators in smart grid demand response markets, IEEE J. Sel. Areas Commun. 31 (7) (2013) $1247-$ 1257.

[6] R. Henriquez Auba, G. Wenzel, D. Olivares, M. Negrete-Pincetic, Participation of demand response aggregators in electricity markets: Optimal portfolio management, IEEE Transactions on Smart Grid PP (99) (2017) 1-1.

[7] A. Bernstein, L. Reyes-Chamorro, J.-Y. Le Boudec, M. Paolone, A composable method for real-time control of active distribution networks with explicit power setpoints. Part I: Framework, Electr. Power Syst. Res. 125 (2015) 254264. 
[8] A. Angioni, et al., A distributed automation architecture for distribution networks, from design to implementation, Sustainable Energy, Grids and Netw. 15 (2018) 3-13.

[9] IDE4L: Ideal grid for all, (Website: http://ide4l.eu).

[10] C. Chen, J. Wang, S. Kishore, A distributed direct load control approach for large-scale residential demand response, IEEE Trans. Power Syst. 29 (5) (2014) 2219-2228.

[11] A. Moser, (on behalf of ENTSO-E), Impact of Merit Order activation of automatic Frequency Restoration Reserves and harmonized Full Activation Times, 29 February 2016 (final version).

[12] G. Del-Rosario-Calaf, S. Rocamora, C. Corchero, Design of an algorithm to deliver demand side flexibility from aggregated resources to distribution system operators, in: 2016 IEEE PES Innovative Smart Grid Technologies Conference Europe, ISGT-Europe, Ljubljana, 2016, pp. 1-6.

[13] Z. Al-Jassim, M. Christoffersen, Q. Wu, S. Huang, G. Del-Rosario-Calaf, C. Corchero, M.A. Moreno, Optimal approach for the interaction between DSOs and aggregators to activate DER flexibility in the distribution grid, in: Proceedings of 24th International Conference on Electricity Distribution, CIRED, Glasgow, 2017 (in press).
[14] M. Á. Moreno, J. Usaola, Technical constraints and flexibility management in smart grids, in: 2015 12th International Conference on the European Energy Market, EEM, Lisbon, 2015, pp. 1-5.

[15] L. Igualada, C. Corchero, M. Cruz-Zambrano, F.J. Heredia, Optimal energy management for a residential microgrid including a vehicle-to-grid system, IEEE Trans. Smart Grid 5 (4) (2014) 2163-2172.

[16] A. Ruiz-Alvarez, A. Colet-Subirachs, F. Alvarez-Cuevas Figuerola, O. GomisBellmunt, A. Sudria-Andreu, Operation of a utility connected microgrid using an IEC 61850-based multi-level management system, IEEE Trans. Smart Grid 3 (2) (2012) 858-865.

[17] Agenzia Regionale per la Protezione dell'Ambiente (ARPA Lombardia), Richiesta dati misurati (Available Online at: http://www2.arpalombardia.it/siti/ar palombardia/meteo/richiesta-dati-misurati/Pagine/RichiestaDatiMisurati.asp $\mathrm{X})$.

[18] Gestore Mercati Energetici, Results and statistics of electricity market (Available Online at: http://www.mercatoelettrico.org/It/Esiti/MGP/EsitiMgp.aspx). 